ORIGINAL ARTICLE

\title{
Worksite health promotion using individual counselling and the effectiveness on sick leave; results of a randomised controlled trial
}

\author{
K I Proper, A J van der Beek, V H Hildebrandt, J W R Twisk, W van Mechelen
}

Occup Environ Med 2004;61:275-279. doi: 10.1136/oem.2002.005769

See end of article for authors' affiliations

Correspondence to: Dr K I Proper, TNO Work and Employment, PO Box 718,2130 AS Hoofddorp, Netherlands;

K.Proper@arbeid.tno.nl

Accepted 17 April 2003

\begin{abstract}
Aims: To investigate the effectiveness of a worksite health promotion programme by individual counselling on sick leave.

Methods: Three municipal services of Enschede, the Netherlands, participated in this trial. A total of 299 civil servants were measured at baseline and were randomised by cluster into the intervention $(n=131)$ or the control group ( $n=168$ ). During nine months, subjects in the intervention group received a total of seven consultations, particularly aimed at increasing their physical activity level and improving their dietary habits. Both the intervention and the control subjects received written information as to several lifestyle factors. Sick leave data regarding the nine month intervention period (from May until January) were collected from each municipal service's personnel department. In addition, sick leave data concerning the nine month period pre- and post-intervention were collected. Sick leave data were analysed using multilevel analysis.

Results: For both groups, the mean sick leave rate during the intervention increased compared to before the intervention. After the intervention period, the control group increased even more (from 22.9 to 27.6 days), whereas the intervention group slightly decreased (from 21.5 to 20.5 days). Median values of sick leave rate decreased for both groups. No statistically significant intervention effect was found. In both groups, the mean sick leave frequency slightly decreased over time (intervention effects were not significant).

Conclusions: Results showed no significant effect of individual counselling on sick leave. Continued research investigating the effectiveness of this individual counselling programme on several health related outcomes is useful to clarify the trend observed in sick leave.
\end{abstract}

uring the past few decades, in both the USA and in European countries, worksite health promotion programmes have increasingly been implemented. ${ }^{12}$ Main factors addressed in such programmes involve physical activity or fitness, and nutrition. Although reasons for implementation may differ between organisations, offering a health promotion programme to employees is generally based on the assumption that it produces benefits to the individual and the organisation. ${ }^{1}$ It is suggested that such programmes will improve health and thereby will contribute to a decrease in sick leave. Although there is indeed some evidence that physical activity or fitness programmes at the worksite are beneficial for the employer in terms of reduced sick leave, strong evidence is still lacking due to the methodological shortcomings of the studies performed and inconsistencies found between the studies. ${ }^{3}$

A promising intervention strategy to promote healthy behaviour concerns individual counselling. Individualised programmes address the actual individual behaviour and thereby meet the specific needs of the individual. For this reason, individual counselling is suggested to be more effective than group based programmes. An example of a tailored intervention is the Patient-centred Assessment and Counselling for Exercise and Nutrition (PACE), ${ }^{56}$ which is based on the transtheoretical model (TTM)..$^{78}$ The TTM is based on the assumption that people make behavioural changes by passing through various stages, namely: (1) precontemplation (not intending to change behaviour); (2) contemplation (considering to change behaviour); (3) preparation (making small changes in behaviour); (4) action (actively engaging in behaviour change); and (5) maintenance (sustaining the behaviour change over time). By using PACE physical activity and nutrition materials together, a comprehensive health promotion programme is provided. The PACE physical activity intervention was developed for primary health care and has, in this setting, proven to be effective in increasing the level of physical activity in the short term. ${ }^{9}$

We studied an intervention using PACE physical activity and nutrition materials at the worksite. This PACE-type intervention at the worksite has been shown to be effective on energy expenditure, physical activity during sports, and cardiorespiratory fitness. ${ }^{10}$ Our hypothesis is that persistent regular physical activity improves health status, thereby leading to less illness, and as a consequence to reduced sick leave. Many studies have shown associations between physical activity and a reduced risk for several chronic diseases. ${ }^{11-13}$ Since chronic diseases cause long term sick leave in particular, one might expect to find effects of a physical activity intervention on long term sick leave, rather than on short spells of sick leave. Some studies that evaluate the effectiveness of a worksite physical activity programme have indeed shown more pronounced effects on long term sick leave than on short term sick leave. ${ }^{14}{ }^{15}$ However, another recent randomised trial could not confirm these findings. ${ }^{16}$ Thus, evidence for the effectiveness of a worksite physical activity programme on (the type of) sick leave still remains obscure. The aim of the present paper is to describe the effectiveness of the PACE-type intervention on sick leave. 


\section{Main messages}

- No statistically significant effect was found of a worksite individual counselling programme on sick leave.

- Both study groups showed an increase in mean sick leave rate with a decrease in the median values.

- In the control group in particular, a continuing increase of long term sick leave was found.

\section{METHODS}

\section{Study population}

Three municipal services of a Dutch town, Enschede, that decided to implement the individual based intervention, participated in the study. Employees meeting the inclusion criteria were invited to attend an information session, during which the content of the intervention as well as the design of the study was explained. The inclusion criteria were: (1) being a civil servant, (2) being a white-collar worker, (3) having a contract for at least 24 hours a week, and (4) having a contract until the moment of post-test.

\section{Randomisation}

Randomisation took place within each municipal service at the level of work unit, given the anticipated contamination of the intervention among colleagues working within the same unit. An unequal number of subjects in the intervention versus the control group ( $45 \%$ versus 55\%, respectively) was arranged, as a larger loss to follow up was expected among control subjects compared to intervention subjects. Although, for practical reasons, the allocation schedule had to be arranged before the baseline measurements, subjects were informed about the group assignment after the baseline measurements. The study protocol was approved by the Medical Ethical Committee of the VU University Medical Centre.

\section{Interventions}

During nine months (from May 2000 until January 2001), all intervention subjects were offered a maximum of seven consultations. Consultation was done by a physiotherapist, who was trained for the use of the PACE protocols. Each consultation took place during working time and was 20 minutes in duration. The counselling was primarily focused at increasing the level of physical activity, and secondarily at improving the dietary habits. If there was time left and only at the specific request of the employee, other topics such as job stress and musculoskeletal symptoms could be addressed. During the first two consultations, PACE physical activity and nutrition materials were used in order to set up a plan to improve the concerned behaviour. Moreover, during the first consultation, intervention subjects received written information about several lifestyle factors (physical activity, nutrition, smoking, job stress, and musculoskeletal symptoms). During the remaining five consultations, the physical activity and nutrition plan was discussed and, if necessary, adjusted.

Subjects in the control group only received the written information about lifestyle factors. This information was given directly after baseline measurements and was exactly the same as the intervention subjects received during the first consultation.

\section{Data collection}

After having signed the written informed consent, all participating employees were measured. Employees were

\section{Policy implications}

- Implementation of an individual counselling intervention at the worksite cannot be motivated by reducing sick leave alone.

- To clarify the trend observed in sick leave, continued research investigating the effectiveness of this individual counselling programme on several health related outcomes is useful.

measured again directly after the intervention. Measurements consisted of a questionnaire, fitness and health tests, and a structured interview. The questionnaire involved demographic factors, physical activity behaviour, health status, and work (stress) related factors. In the fitness and health tests, the following parameters were measured: body height, body weight, blood pressure, total blood cholesterol, waist and hip circumference, and thickness of four skin folds (biceps, triceps, suprailiac, and subscapular). In addition, a submaximal bicycle test was performed in order to estimate the maximum aerobic capacity. ${ }^{17}{ }^{18}$ The structured interview involved physical activities performed in the past seven days. ${ }^{19} 20$

Further, sick leave data were obtained from each municipal service's personnel department. In the records, absences due to holidays and pregnancy were excluded. For the analyses, sick leave data from three periods of the same nine months (from May until January) were used: before (1999-2000), during (2000-2001), and after the intervention (2001-2002).

The outcome measures were: (1) sick leave rate, and (2) frequency of sick leave. Sick leave rate was defined as the total number of sick leave days during the nine month period of concern. In case of partial work disability, the person was considered to be absent from work through illness. Sick leave frequency concerned the number of newly reported cases of sick leave during each period from May until January. An episode of sick leave was defined as a period of sick leave preceded and followed by a period of at least one day at work. ${ }^{21}$

\section{Data analysis}

The statistical analysis was based on the intention-to-treat principle. To study the course of the effectiveness of the intervention on sick leave, longitudinal data analysis was used, correcting for sick leave before the intervention, with both sick leave during and sick leave after the intervention as the outcome measure. Because there were two outcome measures for each subject (sick leave during and after the intervention period), and because of the cluster randomisation, multilevel analysis ${ }^{22}$ was used. In doing so, we first checked whether there was a random intercept by stepwise adding the level of respondent, work unit, and service at the constant variable. We then checked if there was a random slope for the same three levels. Based on the "final" model, we checked for confounding. Both crude and adjusted analyses were carried out. In the crude analysis, the independent variables were group allocation, time, and sick leave before the intervention. In the adjusted analysis, age, gender, education, smoking, physical activity, ${ }^{23}{ }^{24}$ physical fitness (average heart rate during last two minutes of bicycle test), and (work) stress related variables (emotional exhaustion, depersonalisation, feelings of competence (Dutch version of the Maslach Burnout Inventory) $)^{25}$ were added as possible confounders. In case of a change of the effect size of more than $10 \%$, the variable was considered to be a confounder. Further, effect modification was checked for the 
following variables: time, age, gender, and sick leave before the intervention. Effect modification was defined as a significant $(p<0.10)$ interaction term between group allocation and the variable concerned. In case of missing values concerning the possible confounding variables, data were imputed taking the average (for continuous data), or the most frequent category (for nominal or ordinal data).

Subjects who terminated employment at the municipal service, and intervention subjects who participated in a coinciding supervised fitness programme given by the counsellor involved in this project, were excluded from the analyses.

\section{RESULTS}

\section{Study population}

A total of 600 civil servants were invited to attend an information session during which the intervention and the study protocol was explained. Of these, 325 attended this session. After the session, 13 persons refused to participate in the study. Based on the 312 remaining employees, cluster randomisation of work units (70 work units) took place. During baseline measurements, six employees showed up who did not attend the information session and who were willing to participate. Also, 18 employees who attended the information session and who did not sign themselves out for participation, did not show up during baseline measurements. Further, one employee willing to participate had to be excluded, because he did not meet one of the inclusion criteria. Thus, 299 employees meeting the criteria for inclusion were measured at baseline and were assigned to the intervention $(n=131)$, or the control group $(n=168)$. During the intervention two subjects (one in each study group) stopped working at the municipal service. Another 11 subjects terminated employment after the intervention (intervention group: $\mathrm{n}=3$; control group: $\mathrm{n}=8$ ). Further, 33 intervention subjects who were offered to participate in the coinciding supervised fitness programme and who indeed participated at least once, were excluded from the analyses in order to evaluate merely the effect of the individual counselling intervention. The majority of the subjects were highly educated (table 1 ). Though not statistically significant $(p>0.05)$, there were relatively more women in the control group compared to the intervention group $(38.9 \%$ versus $27.8 \%$ ). At baseline, there were no differences between the intervention and control group with respect to sick leave. In addition, there were no differences in sick leave between employees who stopped working and those who continued working at the municipal service.

Table 1 Baseline data of the demographic factors and outcome measures

\begin{tabular}{|c|c|c|}
\hline & $\begin{array}{l}\text { Intervention group } \\
(\mathrm{n}=97)\end{array}$ & $\begin{array}{l}\text { Control group } \\
(\mathrm{n}=167)\end{array}$ \\
\hline Gender (\% female) & 27.8 & 38.9 \\
\hline Age (years)* & $43.8(8.1)$ & $43.7(9.3)$ \\
\hline High educated (\%) & 63.9 & 62.7 \\
\hline Absence rate (days)* & $17.2(42.1)$ & $15.2(41.0)$ \\
\hline Absence rate (days) $\dagger$ & 5.0 & 4.0 \\
\hline $\begin{array}{l}\text { Absence frequency } \\
\text { (times) }^{*}\end{array}$ & $1.3(1.5)$ & $1.3(1.4)$ \\
\hline $\begin{array}{l}\text { Absence frequency } \\
\text { (times) } \dagger\end{array}$ & 1.0 & 1.0 \\
\hline $\begin{array}{l}\text { Prevalence of absence } \\
\text { (\%) }\end{array}$ & 63.9 & 62.9 \\
\hline
\end{tabular}

\section{Compliance}

Of the intervention subjects $(\mathrm{n}=97)$, the majority $(79.4 \%)$ attended five $(n=13)$, six $(n=32)$, or seven $(n=32)$ consultations. Nine intervention subjects did not attend any consultation for several reasons (for example, lack of time, privacy reasons, or forgotten). Next to physical activity and nutrition, $18 \%$ of the intervention subjects reported that the counsellor had also addressed job stress. For musculoskeletal disorders, this was $14 \%$.

\section{Effectiveness on sick leave}

For both groups, the mean sick leave rate increased during the intervention, compared to before the intervention (table 2). The control group showed an increase from 15.2 to 22.9 days, while the intervention group increased from 17.2. to 21.5 days. In the period after the intervention period, the control group increased further (from 22.9 to 27.6 days), whereas the intervention group slightly decreased in mean sick leave rate (from 21.5 to 20.5 days). With regard to the median values of sick leave rate, both groups decreased (table 2). The intervention group decreased from 5.0 days (before) to 4.0 days (during) and to 2.0 days (after). The control group first remained stable (median days of sick leave: 4.0), after which the median value decreased to 2.0 (period after the intervention). Frequency of sick leave showed a slight decrease over time for both groups. The mean sick leave frequency of the intervention group decreased from 1.3 to 1.1 to 1.0 times during the nine month period of concern. For the control group, this was 1.3, 1.2, and 1.1 , respectively.

Multilevel analyses showed no statistically significant effect, either for sick leave rate, or for frequency of sick leave (table 3 ). The adjusted analyses did not change the results (table 3). For sick leave rate, a significant interaction was found between the group allocation and sick leave rate in the period before the intervention: the less days of sick leave before the intervention, the larger the effect size in favour of the intervention. For frequency of sick leave, no effect modification was observed.

\section{DISCUSSION}

The purpose of this study was to investigate the effect of individual counselling at the worksite on sick leave. For companies, reduction of sick leave is often an important effect expectation of such a programme.

It appeared that almost two thirds of all workers had been absent during the nine month period before the intervention. Therefore, one might expect some potential for a decrease in sick leave. However, we did not observe such a decrease. Instead, during the intervention the mean sick leave rate increased for both groups. However, a decreasing trend was observed in the median value of sick leave rate. The different trends observed in mean and median values of sick leave rate was due to a change in the long term sick leave. During the intervention period, in both groups, more subjects had been

Table 2 Mean and median values of sick leave rate (in days) in the period before, during, and after the intervention per study group

\begin{tabular}{llll}
\hline & Before & During & After \\
\hline $\begin{array}{l}\text { Mean (SD) sick leave rate } \\
\text { Intervention group }\end{array}$ & $17.2(42.1)$ & $21.5(53.9)$ & $20.5(52.3)$ \\
$\quad \begin{array}{l}\text { Control group } \\
\text { Median sick leave rate }\end{array}$ & $15.2(41.0)$ & $22.9(56.4)$ & $27.6(62.4)$ \\
$\quad$ Intervention group & 5.0 & 4.0 & 2.0 \\
$\quad$ Control group & 4.0 & 4.0 & 2.0 \\
\hline
\end{tabular}


Table 3 Results of the multilevel analyses to determine the effectiveness on sick leave rate and frequency

\begin{tabular}{lllll}
\hline & Crude "difference"* $^{\text {"SE) }}$ & $95 \% \mathrm{Cl}$ & Adjusted "difference" (SE) & 95\% Cl \\
\hline Rate & $-5.10(4.97)$ & -14.84 to 4.63 & $-6.09(4.82) \dagger$ & -15.53 to 3.36 \\
Frequency & $-0.13(0.12)$ & -0.37 to 0.11 & $-0.10(0.12) \ddagger$ & -0.34 to 0.15 \\
\hline
\end{tabular}

*Differences (and standard errors) between the intervention and control group analysed with multilevel analysis; negative difference is in favour of the intervention group.

†Adjusted for: gender, smoking, and depersonalisation.

$\ddagger$ Adjusted for: age, physical activity during sports, and physical activity during leisure time other than sports.

absent because of long term illness compared to the period before the intervention period. After the intervention period, in the control group, the increase in long term sick leave continued, whereas in the intervention group, a reduction was seen in long term sick leave, resulting in a decrease in the mean sick leave rate.

At the start of the intervention, a large firework disaster occurred in Enschede, which might explain the overall increase of mean sick leave rate during the intervention period. This disaster ended in 22 deaths and ruined an entire neighbourhood (about 1500 damaged houses), leading to a parliamentary inquiry. In particular, one municipal service was involved in this disaster due to the permits provided for the firework storage and the responsibility for providing accommodation for those who had become homeless. Despite this interference, which may have influenced the effect of the counselling to some extent, results are considered to be relevant. Although during the intervention, this service showed a larger increase in mean sick leave rate compared to the other two services, no significant interaction was observed between municipal service and the effect on sick leave. Moreover, we applied a randomised controlled trial design at the level of work units within each municipal service, which resulted in an equal distribution of work units of the service in question over the intervention group and control group. In addition, it is well known that a randomised controlled trial design controls for factors outside one's own control.

The individual counselling concerned has been shown to have a favourable effect on physical activity and fitness in the short term. Health, defined as musculoskeletal symptoms, was not influenced statistically significantly by the counselling intervention. ${ }^{10}$ Based on the assumed positive relation between physical activity, fitness, and health, ${ }^{26}$ it is expected that in the longer term health will improve also, with a subsequent lowering effect on sick leave. Therefore, it is interesting to study whether effects on physical activity will persist, since a longer period of regular physical activity is needed to reach more pronounced health, and thereby sick leave effects. In addition, with reference to the effect modification shown in this study, it might be interesting to study different groups of employees (for example, employees who have been absent long term versus those who have hardly been absent through illness).

As far as we know, no studies have been published on the effectiveness of a worksite physical activity or lifestyle counselling programme based on the transtheoretical model on sick leave. However, several studies have evaluated other types of worksite physical activity programmes on sick leave. Two reviews summarised the available evidence on the effectiveness of worksite physical activity programmes, and both found only limited evidence for a positive effect on sick leave due to methodological shortcomings of most studies. ${ }^{34}$ Therefore, high quality (randomised controlled) studies evaluating the effectiveness on sick leave of worksite health promotion or physical activity programmes on sick leave are needed, and in particular those using an individual based approach. In addition, future research as to the effectiveness of different types of worksite physical activity programmes, for example, group based versus individual based interventions, is useful in order to determine whether the evidence can be explained by the type of programme.

Some methodological issues of the present trial need to be addressed. First, as is common in sick leave data, the data were not normally distributed and were skewed to the right: the majority of the employees was either not absent or absent for only a few days, while a few persons were absent because of illness for a long time, thereby largely contributing to a high mean of the total number of sick leave days. Because of the skewed data distribution, we also presented the median. Although a non-parametric test may seem suitable, we decided to conduct a multilevel analyses. This was acceptable since the model assumptions were tested and fulfilled. The residuals were uncorrelated and normally distributed due to the fact that we performed an analysis of covariance, taking sick leave during and after the intervention period as the outcome variable and adjusting for the sick leave data of the period before the intervention.

Secondly, randomisation took place at the level of work unit, instead of the individual level. Although randomisation by individual is commonly preferred, cluster randomisation is sometimes desirable. In our study, randomisation by unit of workers avoided contamination between employees working within the same unit receiving different interventions. Moreover, randomisation by work unit was expected to enhance the compliance as colleagues might stimulate each other. Nevertheless, the use of cluster randomisation can threaten the validity of standard procedures commonly used in comparative trials to assess the effect of an intervention. ${ }^{27}$ A third methodological issue concerns the power of the study to detect a statistically significant effect on sick leave. At the start of the project, we performed a power analysis. However, the power analysis was based on finding an effect on physical activity, which was our primary outcome measure. Based on our hypothesis (mentioned in the introduction) and the fact that sick leave is a relevant issue for the company, we analysed the effect on sick leave too. Sick leave data are not normally distributed, but skewed and have large standard deviations. As a consequence, a large sample size is required, which is not feasible in many studies, and especially in randomised controlled studies evaluating workplace physical activity or health promotion programmes. This means that the statistical non-significance found might be caused by a power problem. Nevertheless, our results still give a good impression of the effect of the counselling intervention on sick leave. Although we recognise the importance of statistical significance, we like to emphasise that conclusions should not be based on statistical significance alone, but also on the effect size.

In conclusion, no statistically significant intervention effects were found for rate or frequency of sick leave. Although median values of sick leave rate decreased for both groups, after the intervention, a difference for average sick leave rate (six days) was observed between the two groups in 
favour of the intervention. To clarify the sick leave trends observed, continued research evaluating the effectiveness of the individual counselling intervention of concern is recommended.

\section{ACKNOWLEDGEMENTS}

We thank Active Living Papendal, the local city authority of Enschede, and the occupational health service linked to the local authority for their important contribution to the project. Moreover, we thank Zon $\mathrm{Mw}$ and NOC*NSF for their financial support. Body@Work, Research Center Physical Activity, Work and Health is part of the Institute for Research in Extramural Medicine and is a joint initiative of TNO Work and Employment, the VU Medical Center, and TNO Prevention and Health.

\section{Authors' affiliations}

K I Proper, V H Hildebrandt, TNO Work and Employment, Hoofddorp, Netherlands

A J van der Beek, W van Mechelen, Department of Social Medicine and Institute for Research in Extramural Medicine, VU University Medical Centre, Amsterdam, Netherlands

J W R Twisk, Department of Clinical Epidemiology and Biostatistics, and Institute for Research in Extramural Medicine, VU University Medical Centre, Amsterdam, Netherlands

\section{REFERENCES}

1 Griffiths A. The benefits of employee exercise programmes: a review. Work Stress 1996; 10:5-23.

2 Shephard RJ. Financial aspects of employee fitness programs. In: Kerr J, Griffiths A, Cox T, eds. Workplace health, employee fitness and exercise. London: Taylor \& Francis, 1996:29-54.

3 Proper KI, Staal JB, Hildebrandt VH, et al. Effectiveness of physical activity programs at worksites with respect to work-related outcomes: a systematic review. Scand J Work Environ Health 2002;28:75-84.

4 Shephard RJ. Worksite fitness and exercise programmes: a review of methodology and health impact. Am J Health Promot 1996;6:436-52.

5 Patrick K, Sallis JF, Long BJ, et al. A new tool for encouraging activity: Project PACE. Phys Sportsmed 1994;22:45-55.

6 Patrick K, Calfas KJ, Sallis JF, et al. Basic principles of physical activity counseling: Project PACE. In: Thomas RJ, ed. The heart and exercise: a practical guide for the clinician. New York: Igaku-Shoin, 1996:33-50.

7 Prochaska JO, DiClemente CC. Stages and processes of self change of smoking: toward an integrative model of change. J Consul Clin Psychol 1983;51:390-5.
8 Prochaska JO, Marcus BJ. The transtheoretical model-the applications to exercise. In: Dishman RK, ed. Advances in exercise adherence. Illinois: Human Kinetics, 1994:161-80.

9 Calfas KJ, Long BJ, Sallis JF, et al. A controlled trial of physician counseling to promote the adoption of physical activity. Prev Med 1996;25:225-33.

10 Proper KI, Hildebrandt VH, van der Beek AJ, et al. Individual counseling and active lifestyle: a randomized controlled trial in a worksite setting. Am J Prev Med 2003;24:218-26.

11 Pate RR, Pratt M, Blair SN, et al. Physical activity and public health, a recommendation from the Centers for Disease Control and Prevention and the American College of Sports Medicine. JAMA 1995;273:402-7.

12 Wannamethee SG, Shaper AG. Physical activity in the prevention of cardiovascular disease: an epidemiological perspective. Sports Med 2001;31:101-14.

13 Lee IM, Sesso HD, Paffenberger RS. Physical activity and coronary heart disease risk in men-does the duration of exercise episodes predict risk? Circulation 2000;102:981-96.

14 Kerr JH, Vos MCH. Employee fitness programs, sick leave and general wellbeing. Work Stress 1993;7:179-90.

15 Cox M, Shephard RJ, Corey P. Influence of an employee fitness programme upon fitness, productivity and absenteeism. Ergonomics 1981;24:795-806.

16 Nurminen E, Malmivaara A, Ilmarinen J, et al. Effectiveness of a worksite exercise program with respect to perceived work ability and sick leaves among women with physical work. Scand J Work Environ Health 2002;28:85-93.

17 Vos JA, Binkhorst RA. Fietsergometrie bii de begeleiding van training Lochem: De Tijdstroom, 1987.

18 Åstrand P-O, Ryhming I. A nomogram for calculation of aerobic capacity (physical fitness) from pulse rate during submaximal work. J Appl Physiol 1954:7:218-21.

19 Sallis JF, Haskell WL, Wood PD, et al. Physical activity assessment methodology in the five-city project. Am J Epidemiol 1985;121:91-106.

20 Taylor CB, Coffey T, Berra K, et al. Seven-day activity and self-report compared to a direct measure of physical activity. Am J Epidemiol 1984; 120:818-24.

21 De Vet HCW, Heymans MW, Dunn KM, et al. Episodes of low back pain: a proposal for uniform definitions to be used in research. Spine 2002;27:2409-16.

22 Goldstein H. Multilevel statistical models. London: Edward Arnold, 1995.

23 Baecke JAH, Burema J, Frijters JER. A Short questionnaire for the measurement of habitual physical activity in epidemiological studies. Am J Clin Nutr 1982;36:936-42.

24 Pols MA, Peeters PH, Ocke MC, et al. Relative validity and repeatability of a new questionnaire on physical activity. Prev Med 1997;26:37-43.

25 Schaufeli WB, Van Dierendonck D. UBOS-manual. Lisse: Swets \& Zeitlinger, 2000 (in Dutch).

26 Bouchard C, Shephard RJ. Physical activity, fitness, and health: the model and key concepts. In: Bouchard C, Shephard RJ, Stephens T, eds. Physical activity, fitness and health. International proceedings and consensus statement. Champaign: Human Kinetics Books, 1994:77-88.

27 Donner A, Klar N. Methods for comparing event rates in intervention studies when the unit of allocation is a cluster. Am J Epidemiol 1994;140:279-89. 